Shozsmith, J. G. \& Shrenis, J. C. (1960). J. gen. Microbiol. 22, 10-24,

\title{
Studies on the Mechanism of Arginine-Activated Motility in a Pseudomonas Strain
}

\author{
By J. G. SHOESMITH AND J. C. SHERRIS* \\ Department of Bacteriology, University of Manchester
}

\begin{abstract}
SUMMARY: A strain of Pseudomonas whose motility could be activated under anaerobic conditions by arginine was shown to decompose arginine to ornithine by enzymic reactions involving citrulline and adenosine phosphates. The enzymes were readily separable from the particulate cell fractions and were not associated with the external flagellar apparatus. Citrulline also activated anaerobic motility but only after a period of pre-aeration or subsequent to its aerobic intracellular synthesis from ornithine. Permeability experiments suggested strongly that the cells of the pseudomonad were more permeable to arginine and citrulline under aerobic than anaerobic conditions. The promotion of motility by citrulline and the dependence of arginine-activated motility on the activity of the arginine dihydrolase system indicate that arginine acts as a direct source of energy for motility.
\end{abstract}

In a previous communication (Sherris, Preston \& Shoesmith, 1957) it was reported that a strain of Pseudomonas remained actively motile for prolonged periods under aerobic conditions ('general aerobic motility') in simple aqueous suspension, but that under anaerobic conditions it was completely non-motile. When arginine was added to the suspension, however, motility was apparent also under anaerobic conditions ("arginine-activated motility'), and there was an approximately linear relationship between arginine concentration, over the range $8 \mathrm{~mm}$ to $2^{-6} \times 3 \mathrm{~mm}$, and the duration of anaerobic motility. There was no evidence of arginine breakdown under aerobic conditions, but under anaerobic conditions arginine was broken down at a constant rate to give one molecule of ornithine and two molecules of ammonia from each arginine molecule. Concurrent studies of arginine breakdown and motility of the organism showed that the period of arginine breakdown corresponded with that of arginine-activated motility.

These observations raised the question of the mechanism of arginineactivated motility. Two main possibilities had to be considered: first, that energy for motility was derived from the breakdown of arginine, and secondly, that arginine was required for activation of a separate system and that its breakdown, while limiting the duration of its activity, played no direct part in supplying the energy for motility. If the first of these processes was operative, it seemed most probable that the breakdown of arginine was by the dihydrolase system (Hills, 1940) involving citrulline as an intermediate, and that adensoine triphosphate (ATP) produced during the citrulline-ornithine step (Slade, Doughty \& Slamp, 1954; Knivett, 1954a) furnished the immediate source of energy for motility under the conditions of the test.

* Present address: Microbiology Laboratory, Teaching Hospital, University of Washington, Seattle 5, U.S.A. 
However, no experimental evidence in support of this hypothesis was available at that time. A possible indirect mechanism which was proposed involved the mediation of the phosphagen, phosphoarginine, in a series of cyclical reactions similar to those obtaining in invertebrate muscle for supplying ATP for the locomotor apparatus. Here again, experimental evidence to support or refute this possibility was not available as the effect of phosphoarginine had not been tested. This communication is concerned with the results of further experiments designed to distinguish between these two possibilities and to throw more light on the mechanism of arginine-activated motility.

\section{MATERIAL AND METHODS}

Organisms used. Except where stated otherwise the organism studied was the pseudomonad described previously (Sherris et al. 1957). The other strains used were a recently isolated strain of $P$. pyocyanea, the strain of Pseudomonas used by Dr H. D. Slade in his studies (Slade et al. 1954), and 8 strains of $\boldsymbol{P}$. fluorescens and $\boldsymbol{P}$. pyocyanea from the culture collection of the Department of Bacteriology, University of Manchester.

Preparation of bacterial suspensions. After overnight growth on nutrient agar at $23^{\circ}$ the bacteria were harvested and suspended in M/60 Sørensen phosphate buffer, pH 7·2. For experiments involving microscopical observation only this suspension was standardized with a Hilger 'Biochem' absorptiometer so that the final concentration was equivalent to $0.5 \mathrm{mg}$. bacteria dry wt. $/ \mathrm{ml}$. (c. $4 \times 10^{9}$ organisms $/ \mathrm{ml}$. or equivalent to Brown's opacity tube no. 5) and used without further treatment. For all other experiments the suspension was washed by centrifugation before being resuspended in $\mathrm{M} / 30$ phosphate buffer $\mathrm{pH} 7 \cdot 2$ and adjusted to the required concentration with the absorptiometer.

Preparations for microscopical examination. Bacterial suspensions were examined for motility under the microscope in the flat glass capillaries described previously (Sherris et al. 1957).

Preparation of cell-free extracts. The organism was grown overnight on $1.5 \%$ nutrient agar in $20 \times 25 \mathrm{~cm}$. enamel trays at $23^{\circ}$. The growth was washed twice before being resuspended in water to give a $20 \%(v / v)$ concentration of packed cells. Portions of $15 \mathrm{ml}$. were placed in a $22 \times 65 \mathrm{~mm}$. flat-bottomed glass tube surrounded by iced water and exposed for $10 \mathrm{~min}$. to ultrasonic vibrations by placing the tip of the $D$ stub of a Mullard Ultrasonic Drill just under the surface. This treatment caused a fall of $90 \%$ in the optical density of the suspension. The disintegrated material was then centrifuged at 25,000 r.p.m. for $80 \mathrm{~min}$ in a Spinco model $\mathrm{L}$ refrigerated centrifuge. The supernate was removed and either lyophilized or stored in the frozen state.

Measurement of cell permeability. Permeability of the cells of the pseudomonad to a number of reagents was detected using the effect described by Mager, Kuczynski, Schatzberg \& Avi-Dor (1956). Suspensions were made in M/50 phosphate buffer $\mathrm{pH} 7 \cdot 2$ containing $0.5 \%$ glucose and adjusted to contain $2 \cdot 0 \mathrm{mg}$. bacterial dry $\mathrm{wt} . / \mathrm{ml}$. The suspension was diluted with $3 \mathrm{vol}$. of 
a solution of the substance under test so that the final concentration was 0.25 M. The changes of optical density with time were then noted. For experiments under anaerobic conditions the absorptiometer tube was sealed with a rubber stopper bored to take a tube through which the air could be removed. The solution of the substance to be tested was placed in the tube and the dissolved gases removed as far as possible under reduced pressure. The bacterial suspension was allowed to attain reduced conditions in a hypodermic syringe and then injected through the rubber stopper. Tests using suspensions containing methylene blue as an indicator showed that anaerobic conditions could be attained in this way.

Analyses. Arginine was estimated by the method of Rosenberg, Ennor \& Morrison (1956) except in the case of some early experiments when the method of Sakaguchi (1950) was used. Citrulline was estimated by the method of Archibald (1944), ornithine by that of Chinard (1952) and ammonia by that of Lubochinsky \& Zalta (1954). The intensities of the colours formed in these reactions were measured in the Hilger 'Biochem' absorptiometer or, in the case of citrulline, at $490 \mathrm{~m} \mu$ in a Unicam S.P. 600 spectrophotometer.

\section{RESULTS}

The nature of the arginine-decomposing enzyme system

In our previous experiments (Sherris et al. 1957) analysis of the reaction products of the decomposition of arginine by the pseudomonad showed that all the arginine could be accounted for by the ornithine and ammonia formed. The absence of significant urease activity strongly suggested the presence of an arginine dihydrolase system but this was not demonstrated conclusively. The experiments described below were designed to settle this point.

Cell-free extracts were mixed with equal volumes of $10 \mathrm{~mm}$ arginine in $\mathrm{M} / 30$ phosphate buffer $\mathrm{pH} 7 \cdot 0$ and incubated at $23^{\circ}$; samples from the mixtures were examined by paper chromatography initially and after $1 \mathrm{hr}$. The chromatograms were run with an ascending boundary using phenol saturated with water as the mobile phase and the spots were located by spraying with a ninhydrin solution. In these experiments traces of ornithine and citrulline were detected and the amounts formed were increased by the addition of $5 \mathrm{~mm}$ adenosine diphosphate (ADP) with $1 \mathrm{~mm}$ magnesium sulphate; these substances have been shown to be necessary for the citrulline ureidase activity of a pseudomonad (Slade et al. 1954).

Similar results were obtained in quantitative experiments. Cell-free extracts were mixed with equal volumes of $1 \mathrm{~mm}$ arginine or $1 \mathrm{~mm}$ citrulline in M/30 phosphate buffer $\mathrm{pH} \mathrm{7.0} \mathrm{both} \mathrm{in} \mathrm{the} \mathrm{presence} \mathrm{and} \mathrm{absence} \mathrm{of} \mathrm{ADP.}$ At the end of $40 \mathrm{~min}$. incubation at $23^{\circ}$ trichloracetic acid (TCA) was added to $5 \%(\mathrm{w} / \mathrm{v})$ concentration, the precipitate removed by centrifugation, and the supernates analysed for arginine and citrulline. In a similar experiment with another preparation sodium dithionite (0.02\%) was added to produce the reducing conditions which are necessary for arginine breakdown by whole cells (Sherris et al. 1957). The results of these experiments (Table 1) showed that 
significant breakdown of arginine and citrulline occurred only in the presence of ADP. The slight activating effect of sodium dithionite as compared with ADP makes it unlikely that reducing conditions directly activate the enzyme system.

Extracts which had been dialysed against water at $5^{\circ}$ were found to have lost all enzyme activity. The ability to break down arginine was restored by addition of adenylic acid (AMP) or ADP, but the citrulline-decomposing activity could not be restored in this way.

Table 1. The breakdown of arginine and citrulline by cell-free extracts of the pseudomonad at $\mathbf{2 3}^{\circ}$

Extracts incubated with $0.5 \mu \mathrm{mole} / \mathrm{ml}$. amino acid

(a) Cell-free extract Cell-free extract + ADP (1 $\mu \mathrm{mole} / \mathrm{ml}$.)

(b) Cell-free extract Cell-free extract $+0.02 \%$ sodium dithionite Cell-free extract + mM ADP Cell-free extract + mM-ADP $0.02 \%$ sodium dithionite

\begin{tabular}{|c|c|c|}
\hline \multicolumn{2}{|c|}{ Arginine } & \multirow[b]{2}{*}{$\begin{array}{c}\text { Citrulline } \\
\text { concentration } \\
\mu \text { mole } / \mathrm{ml} \text {. } \\
\text { after } 40 \mathrm{~min}\end{array}$} \\
\hline $\begin{array}{c}\text { Arginine } \\
\text { concentration } \\
\mu \mathrm{mole} / \mathrm{ml} \text {. } \\
\text { after } \mathbf{4 0} \mathrm{min} \text {. }\end{array}$ & $\begin{array}{c}\text { Citrulline } \\
\text { concentration } \\
\mu \text { mole } / \mathrm{ml} \text {. } \\
\text { after } 40 \mathrm{~min} \text {. }\end{array}$ & \\
\hline 0.82 & 0.12 & 0.89 \\
\hline o & $\mathbf{0 . 8 0}$ & 0.28 \\
\hline 0.48 & - & - \\
\hline 0.40 & - & - \\
\hline $0 \cdot 19$ & - & - \\
\hline 0.12 & - & - \\
\hline
\end{tabular}

These results make it clear that citrulline is an intermediate in the breakdown of arginine and also that adenosine phosphates are involved. The enzyme system is therefore of a similar type to the arginine-decomposing systems found in other bacteria (Oginsky \& Gehrig, 1952; Knivett, 1954a; Korzenovsky \& Werkman, 1952; Schmidt, Logan \& Tyrell, 1952; Slade, 1958; Slade et al. 1954), but differs from them in that AMP or ADP is necessary for the breakdown of both arginine and citrulline. The enzymes responsible for the overall reaction will in future be referred to as the 'arginine dihydrolase' system and those responsible for the arginine-citrulline and citrulline-ornithine steps as 'arginine-desimidase' and 'citrulline-ureidase' respectively.

\section{The site of enzyme activity}

Investigations with intact and sonically disrupted cells were made to determine the site of enzyme activity. Cells washed four times in $\mathbf{m} / \mathbf{3 0}$ buffer showed no change in their ability to decompose arginine or show arginineactivated motility, indicating a close association of the enzymes with the cell. Another cell suspension $(20 \%, v / v)$ was treated with ultrasonic vibrations and then centrifuged at $41,000 \mathrm{~g}$. Three fractions were obtained by this means, a clear supernate, and a deposit consisting of an upper opalescent layer and a lower opaque layer. The supernate was removed, the deposit washed and resuspended in $0.85 \%(\mathrm{w} / \mathrm{v}) \mathrm{NaCl}$ and separated into two fractions by differential centrifugation at $4200 \mathrm{~g}$ and $41,000 \mathrm{~g}$. Each fraction was then resuspended in the same volume of $0.85 \% \mathrm{NaCl}$ as the original supernate. The 
three sonic lysate fractions were each tested for their ability to break down arginine and citrulline by mixing an equal volume of the fractions to be tested with a $1.0 \mathrm{~mm}$ solution of the amino acid in $0.04 \mathrm{M}$ buffer which also contained $1.0 \mathrm{mM}-\mathrm{ADP}$ and $2 \times 10^{-3} \mathrm{M}-\mathrm{MgSO}_{4}$. The mixtures were incubated at $23^{\circ}$ and the reaction stopped by addition of TCA to $5 \%(w / v)$ concentration. The results are shown in Table 2.

Table 2. Breakdown of arginine and citrulline by fractions of cell-free extracts

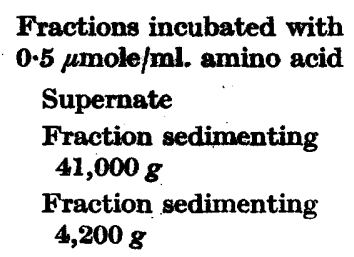

\begin{tabular}{|c|c|}
\hline $\begin{array}{c}\text { Arginine } \\
\text { remaining } \\
\text { after } \mathbf{8 0} \mathrm{min} . \\
(\mu \mathrm{mole} / \mathrm{ml} .)\end{array}$ & $\begin{array}{c}\text { Citrulline } \\
\text { remaining } \\
\text { after } 90 \mathrm{~min} . \\
(\mu \mathrm{mole} / \mathrm{ml} .)\end{array}$ \\
\hline 0.05 & $0 \cdot 21$ \\
\hline 0.42 & 0.40 \\
\hline 0.50 & $0 \cdot 44$ \\
\hline
\end{tabular}

In another experiment a suspension of the pseudomonad was deflagellated by agitation in a homogenizer (Measuring and Scientific Equipment Ltd.) as described by Stocker (1956), and washed by centrifugation. The absence of flagella on the organisms in the treated suspension and their presence on those of the control was established by examination of films stained by the method of Preston \& Maitland (1952) and by examining for motility. Counts of the numbers of viable organisms in the two suspensions gave similar results. The deflagellated suspension and the control were then tested for the ability to break down arginine and found to decompose it at identical rates. Flagella severed from the bacteria by agitation and freed from cells by differential centrifugation were tested and found to be unable to break down arginine in the presence of ADP and magnesium ions.

These experiments show that the arginine-decomposing enzymes are not associated with the external flagellar apparatus. The distribution of enzymic activities in the fractions of lysed suspensions also indicates that the enzymes are not associated with readily sedimentable particles and so are unlikely to be located in the cell wall.

\section{Investigation of the possible role of phosphoarginine}

A number of experiments were made to test the hypothesis that phosphoarginine was involved in supplying energy for motility. Phosphoarginine $(0.4 \mathrm{~mm})$ did not promote anaerobic motility in a suspension of the organism and estimations of phosphoarginine in the suspension showed no change over a period of $1.5 \mathrm{hr}$. Since this negative result could have been due to impermeability of the cells to phosphoarginine a similar experiment was performed using a disintegrated $20 \%(v / v)$ cell suspension; again no hydrolysis of phosphoarginine could be detected, either with or without the addition of ADP and $\mathrm{Mg}^{++}$ions. Other experiments were made to determine whether phos- 
phoarginine could be detected in the cells of the pseudomonad. Chemical fractionation (Ennor, Morrison \& Rosenberg, 1956) of $20 \mathrm{ml}$. of ultrasonic lysates of similar aerated and unaerated $10 \%(\mathrm{v} / \mathrm{v})$ cell suspensions yielded only a slight barium- and alcohol-insoluble precipitate. When this was dissolved in $1 \mathrm{ml}$. of water no substance hydrolysable to arginine was found to be present. There is thus no experimental evidence for the participation of phosphoarginine in the activation of motility.

\section{The effect of inhibitors}

A number of reagents were tested over a range of concentrations to determine whether they would inhibit either the citrulline-ureidase reaction specifically, or the complete arginine-dihydrolase system, without affecting motility. These included canavanine sulphate, L-ornithine hydrochloride, citrulline, $\mathrm{NaN}_{3}, \mathrm{KCN}, \mathrm{Na} p$-chloromercuribenzoate, $\mathrm{Na}$ iodoacetate, $\mathrm{KIO}_{4}, \mathrm{Na}$ ethylenediamine tetra-acetate, $\mathrm{NaF}$, and 8-hydroxyquinoline at $\mathrm{pH} \mathbf{7 \cdot 2}$. The effect of $\mathrm{pH}$ over a range of 3-10 was also tested. None of these caused a specific inhibition of the citrulline-ureidase, and of those which had no effect on aerobic motility only three affected the arginine-dihydrolase. At pH 8.5 or in the presence of $10 \mathrm{~mm}$-ornithine the rate of arginine breakdown was decreased, and at $\mathrm{pH} \mathrm{9.5}$ or with $10^{-4} \mathrm{M}$ - $p$-chloromercuribenzoate breakdown was completely prevented. Although aerobic motility was not inhibited, each of these agents inhibited arginine-activated motility of an extent which paralleled its action on the breakdown of arginine. This observation strongly. suggests that it is the process of arginine decomposition rather than the presence of arginine itself which activates motility.

\section{Evidence that citrulline breakdown supplies energy for motility}

Activation of motility by citrulline. If the breakdown of arginine by the arginine dihydrolase system furnishes energy for motility it would be anticipated that citrulline would also be active since its breakdown to ornithine has been shown to be associated with the formation of ATP. Repeated attempts to induce anaerobic motility with citrulline failed however when citrulline was added to the suspension of the pseudomonad immediately before filling capillary tubes. This lack of activity was attributed to impermeability of the cell to citrulline under anaerobic conditions.

Cells were treated with a number of reagents in an attempt to alter their permeability to citrulline; these comprised anionic, cationic and neutral surface-active agents over a range of concentrations, several antibiotics, glycerol, and buffers of pH 5, 6,7 and 8. Suspensions were also heated at various temperatures and exposed to u.v. radiation. The treated cells were examined microscopically for motility in the presence of $0.5 \mathrm{~mm}$-citrulline both with and without added ADP. In the same series of experiments the ability of $0.5 \mathrm{~mm}$-ATP to activate motility was also tested. In no case was any motility found in the presence of citrulline or ATP. In an attempt to select a citrulline-permeable variant of the pseudomonad, the organism was 
grown in a medium containing citrulline as the sole source of carbon and nitrogen; cells from these cultures, however, although able to show arginine-activated motility, were not motile in citrulline solutions. In addition, nine other strains of Pseudomonas sp. including that used by Dr H. D. Slade (Slade et al. 1954) were examined; all showed arginine-activated motility and decomposed arginine, but none showed any motility in the presence of citrulline.

In the experiments described above citrulline was added to the suspension immediately before observations began, and the period of contact with citrulline was therefore almost entirely under anaerobic conditions. Some preliminary experiments indicated that citrulline could, however, pass into the cell under aerobic conditions, and experiments were therefore undertaken to determine whether such intracellular citrulline could activate anaerobic motility.

Reaction mixtures of equal parts of a suspension of the pseudomonad (Brown's tube no. 10) in $\mathrm{M} / 30$ Sørensen's phosphate buffer $\mathrm{pH} 7 \cdot 2$ and of DL-citrulline $1.0 \%(\mathrm{w} / \mathrm{v})$ were aerated by gentle agitation in shallow layers for $120 \mathrm{~min}$. Control tubes containing $0.5 \mathrm{~mm}$-arginine and without added amino acid were similarly treated. Capillary tubes were filled from these preparations immediately after the aeration period was complete, and the organisms were examined for the duration of general aerobic motility and for the presence and duration of continued anaerobic motility. Following the cessation of general aerobic motility definite motility expressed as progression, rotation or marked vibration was observed in the citrulline-containing tube for $37 \mathrm{~min}$., in the arginine-containing tube for $47 \mathrm{~min}$., and in the control tube for less than 4 min. Continuing anaerobic motility in citrulline was slower and affected fewer cells at any given time than did arginine-activated motility, but was, nevertheless, quite unequivocal. It followed the period of general aerobic motility without the brief interruption that was seen in the case of arginine-activated motility (Sherris et al. 1957), and was most rapid immediately after the period of general aerobic motility.

The effect of varying the conditions of test and the concentration of reagents on this citrulline-activated motility was investigated and the results are briefly summarized below. Motility in these experiments was considered to have ended when no further progressive movement could be seen. Unless otherwise stated the mixtures were aerated for $\mathbf{3 0} \mathbf{~ m i n}$. at room temperature. L-Citrulline was added to a final concentration of $5 \mathrm{mM}$, glucose to $0.5 \%$, phosphate buffer to $\mathrm{M} / 60$ and the pseudomonad to an opacity equivalent to Brown's tube No. 5.

Addition of glucose. The addition of glucose (final concentration of $0.5 \%$ ) to reaction mixtures was found to reduce to less than $10 \mathrm{~min}$. the period of general aerobic motility which followed aeration. This facilitated measurement of the duration of anaerobic motility and glucose was, consequently, added in all subsequent experiments. Lower concentrations of glucose $(0.1$ and $0.02 \%)$ had similar, though progressively less marked, effects on the duration of general aerobic motility. The duration of citrulline-activated motility was approximately $20 \mathrm{~min}$. in all these experiments and was un- 
influenced by the presence of concentration of glucose and by whether glucose was added before or after aeration.

The concentration of citrulline. L-Citrulline was added to reaction mixtures in concentrations of $5,1.25,0.2$ and $0.05 \mathrm{~mm}$. The durations of citrullineactivated anaerobic motility were respectively 28, 28, 28 and $0 \mathrm{~min}$. This experiment, which was repeated several times, indicated that above a certain limiting concentration, the duration of motility was not significantly affected by the concentration of citrulline outside the cell.

The concentration of organisms. Cells of the pseudomonad were added to reaction mixtures in concentration equivalent in opacity to $4 \times, 2 \times$ and $1 \times$ Brown's tube no. 5. The durations of citrulline-activated motility were respectively 17, 18 and $20 \mathrm{~min}$. Differences in bacteria concentration over this range thus had little influence on the results.

Duration of aeration. Reaction mixtures were aerated for 1, 5, 10, 15 and $20 \mathrm{~min}$; ; the duration of citrulline-activated motility was approximately $20 \mathrm{~min}$. after aeration for 10,15 and $20 \mathrm{~min}$., $11.5 \mathrm{~min}$. after aeration for $5 \mathrm{~min}$., and $4.5 \mathrm{~min}$. after the shortest aeration period. It thus appears that an aeration of between 10 and $15 \mathrm{~min}$. suffices for the maximum development of citrulline-activated motility.

The fate of citrulline in aerated suspensions. A bacterial suspension (2.5 mg. bacterial dry wt./ml.) in 0.04 M-phosphate buffer $\mathrm{pH} 7 \cdot 2$ containing $1 \mathrm{~mm}$ L-citrulline and $0.5 \%$ glucose was aerated at $18^{\circ}$ by shaking for $80 \mathrm{~min}$. It was then transferred to a tube in which only a small surface was in contact with the air, to allow reducing conditions to develop. A control suspension without citrulline was similarly treated and a further control with citrulline was maintained throughout the experiment without aeration. Samples were withdrawn at $0,15,30,50,70$ and $90 \mathrm{~min}$. and added to TCA of a final concentration of $1 \%$. The samples were then heated for $10 \mathrm{~min}$. at $100^{\circ}$, centrifuged, and the supernates analysed for arginine, ornithine and ammonia. The standards for the ornithine estimations by the method of Chinard (1952) were such that the combined concentrations of citrulline and ornithine was $1 \mathrm{~mm}$. This was necessary as citrulline formed some colour in the reaction and also caused the calibration curve to deviate from a straight line. In other experiments citrulline analyses were also made but the reproducibility of the method of estimation was not sufficient for the determination of small percentage differences in concentration.

The results of these experiments are shown in Fig. 1. It is apparent that ammonia and ornithine were formed in larger amounts by the pre-aerated than by the unaerated suspension. No arginine was detectable in any experiment.

The rapid and similar increase in the ammonia and ornithine concentrations in the pre-aerated suspension appears to indicate that the citrulline was being decomposed by a citrulline-ureidase reaction. Like the citrulline-activated motility, this decomposition followed the period of pre-aeration in citrulline, and this correlation suggests that citrulline and arginine act as stimulators of motility by similar mechanisms. The small amount of citrulline breakdown 
occurring in the unaerated suspension appears to be due to the inevitable aeration involved in mixing the suspension and citrulline solutions, but is not sufficient to induce motility.

The effect of other amino acids. To test the specificity of the phenomenon twenty-one amino acids were tested in final concentrations of $5 \mathrm{~mm}$. They were: glycine, DL-alanine, DL-valine, DL-leucine, DL-isoleucine, DL-serine, DL-threonine, L-cysteine, DL-methionine, L-aspartic acid, L-asparagine, L-glutamic acid, DL-lysine, L-arginine, L-citrulline, L-ornithine, creatine, DL-histidine, L-proline, L-hydroxyproline, DL-phenylananine. Only three of these, L-citrulline, L-arginine and L-ornithine, gave continuing anaerobic motility after the period of general aerobic motility had ceased. The durations of anaerobic motility were: citrulline $19 \mathrm{~min}$., arginine $>90 \mathrm{~min}$., ornithine $19 \mathrm{~min}$.

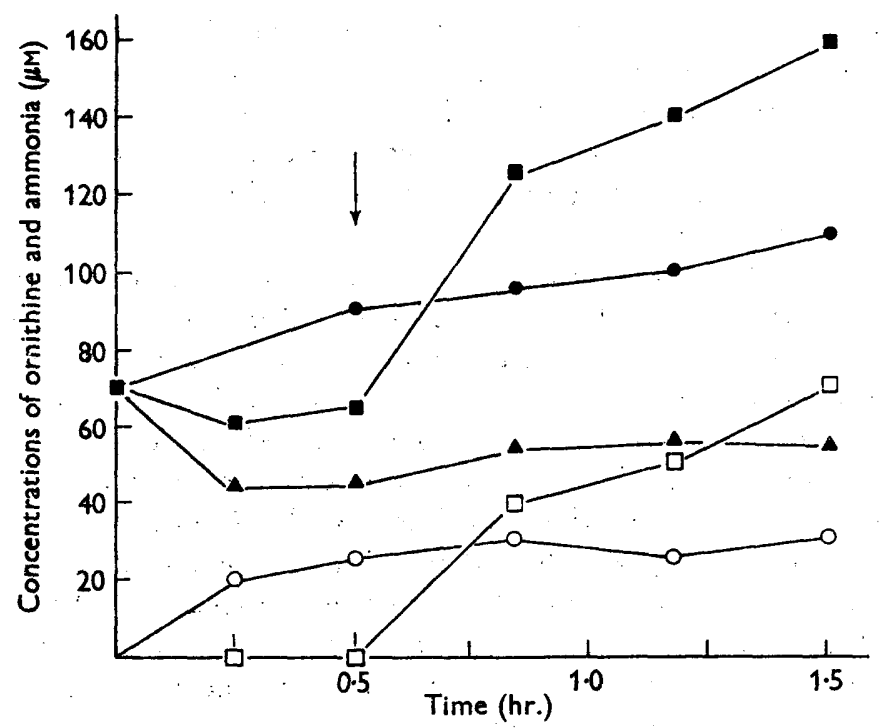

Fig. 1. The formation of ornithine and ammonia from citrulline. - -0 , Ornithine concentration in unaerated suspension; $-\square-$, ornithine concentration in suspension aerated for 80 min; - - , ammonia concentration in unaerated suspension; - - ammonia concentration in suspension serated for $80 \mathrm{~min}$; - $-\Delta-$, ammonia concentration in suspension aerated for $\mathbf{8 0} \mathrm{min}$. in absence of citrulline. No ornithine was found in this suspension. The arrow indicates the point at which aeration ceased in the aerated suspensions.

Activation of motility by ornithine under these conditions was unexpected and experiments were made to determine the factors responsible. Variation of the conditions of test and of the concentrations of reagents showed that both aeration and the presence of glucose during the aeration period were required for the satisfactory development of ornithine-activated motility, and that differences in concentration of ornithine over the range 20 to $1.25 \mathrm{~mm}$ had little effect on the duration of the phenomenon.

Experiments were made to determine the substances involved in this ornithine-activated motility. A suspension of the pseudomonad was aerated 
for $1 \mathrm{hr}$, at $18^{\circ}$ in the presence of $5 \mathrm{~mm}$-L-ornithine hydrochloride and $0.5 \%$ glucose. A control suspension was aerated in the absence of ornithine and others maintained anaerobically both with and without added ornithine. After $1 \mathrm{hr}$. the suspensions were heated for $15 \mathrm{~min}$. at $100^{\circ}$, the bacteria removed by centrifugation and the supernates examined by chromatography. In addition to an intense ornithine spot a weak spot corresponding to citrulline was found in the sample from the aerated suspension containing ornithine, but not in the other samples. No spot corresponding to arginine was found and no arginine was detectable, by colorimetric tests, in the supernates. Tests for the ureido group by the method of Archibald (1944) gave a positive result in aerated suspensions containing ornithine and examination of the absorption spectrum on the colour showed it to be identical in form with that given by citrulline. This, together with chromatographic evidence, indicated that the substance formed was citrulline.

Table 3. The symthesis of citrulline from ornithine by the pseudomonad

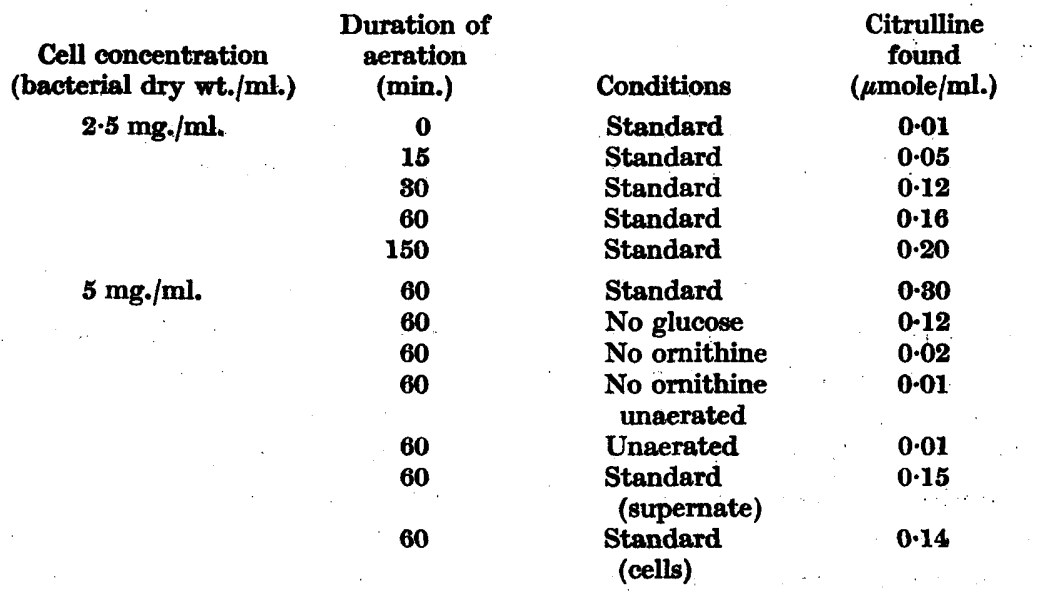

The standard conditions under which this experiment was performed consisted of aeration at $18^{\circ}$ of a suspension in $0.04 \mathrm{M}$-phosphate buffer $\mathrm{pH} 7 \cdot 2$ containing ornithine hydrochloride ( $5 \mu \mathrm{mole} / \mathrm{ml}$ ) and glucose ( $0.05 \%)$, followed by addition of TCA to $1 \%$ concentration, heating at $100^{\circ}$ for $10 \mathrm{~min}$., centrifugation and estimation of citrulline in the supernatant.

The results of quantitative citrulline estimations under the various conditions are shown in Table 3, and other experiments showed that there was no increase in the amount formed when the ornithine concentration was raised to $10 \mathrm{~mm}$ and when ammonium sulphate and sodium bicarbonate were each added in $10 \mathrm{~mm}$ concentration both separately and together. These results confirm that citrulline is formed in greatest concentrations when the suspensions are aerated in the presence of ornithine and glucose. These are the conditions which best promoted ornithine-activated motility and make it extremely probable that citrulline is the substance responsible. There is one difference, however; the amount of citrulline formed increases with time 
whereas the duration of ornithine-activated motility is not dependent on the duration of aeration. It is possible that the observation by Knivett (1954b), that ornithine inhibited the breakdown of citrulline in extracts of Streptococci may be of some significance here. In the experiments with intact cells of Pseudomonas, however, such inhibition could not be direct since the ornithine concentration remained roughly constant, and, in addition, other experiments in which ornithine was used to inhibit arginine breakdown, showed that no accumulation of citrulline occurred and that the reaction proceeded to completion. It would seem more probable that the explanation is to be found in the results given in Table 8 which show that after $1 \mathrm{hr} .50 \%$ of the citrulline formed has diffused into the supernatant. This suggests that the quantity of citrulline available for activating motility is limited by the resultant of two opposing processes, the synthesis of citrulline on one hand and its diffusion out of the cell on the other.

These experiments show that motility can be activated by citrulline only under special conditions in which breakdown of citrulline also occurs; they also show that a similar degree of motility can be promoted by ornithine under conditions in which citrulline synthesis occurs. The demonstration of motility activated by citrulline would be expected from the hypothesis that arginine breakdown by the dihydrolase reactions provides energy for motility and thus provides good evidence that this hypothesis is correct.

\section{The permeability of the pseudomonad to arginine, citrulline and ornithine}

The experiments described above have shown that citrulline did not activate motility when added to a suspension under anaerobic conditions but did so after a preliminary period of aeration. It was thought that this might be explained by an increased permeability to citrulline under aerobic conditions and experiments were performed to investigate this point.

The use of a thick suspension technique (Mitchell, 1953) to investigate permeability to citrulline at $18^{\circ}$ did not yield any conclusive results. This was because citrulline was found to be decomposed at the slow rate of $0.05 \mu \mathrm{mole} / \mathrm{ml} . / \mathrm{hr}$. in aerated $0.5 \mathrm{mg} . / \mathrm{ml}$. suspensions at $18^{\circ}$ and at $0.002 \mu \mathrm{mole} / \mathrm{ml} . / \mathrm{hr}$. in similar unaerated suspensions. The fact that citrulline was decomposed indicates the presence of some degree of permeability but makes it difficult to draw conclusions from analyses of the supernates of thick suspensions containing added citrulline. Analyses of the deposits from centrifuged suspensions showed however that within $15 \mathrm{~min}$. of its addition citrulline was present in the bacterial deposit in the same concentration (10 mM) as in the supernate, in both aerated and unaerated suspensions at $18^{\circ}$. This finding could be explained either by rapid permeability or simple physical adsorption on the surface of the cell. In view of this uncertainty another method was used.

In this method (Mager et al. 1956) use is made of the ehanges in optical density which occur when suspensions are made in solutions of differing osmotic pressure. Cells were suspended in $M / 200$ buffer at $18^{\circ}$ and in buffer containing 
respectively $0.25 \mathrm{M}-\mathrm{NaCl}, 0.25 \mathrm{M}-\mathrm{L}$-arginine hydrochloride, $0.25 \mathrm{M}$-L-citrulline, or $0.25 \mathrm{M}-\mathrm{L}$-ornithine hydrochloride and the changes in optical density followed. It is evident (Fig. $2 a$ ) that the amino acids pass into the cells at different rates. Under anaerobic conditions (Fig. $2 b$ ) ornithine behaved as under aerobic conditions but with arginine and citrulline no change in the optical density of suspensions occurred until conditions became aerobic, indicating that permeation of these amino acids is facilitated under aerobic conditions. These observations are at first sight incompatible with the knowledge that arginine is metabolized under anaerobic conditions. The rate of arginine breakdown is however only $1 \mu \mathrm{mole} / \mathrm{ml} . / \mathrm{hr}$. which could easily occur with a rate of entry of arginine into the cell too small to be evident as a change in optical density.
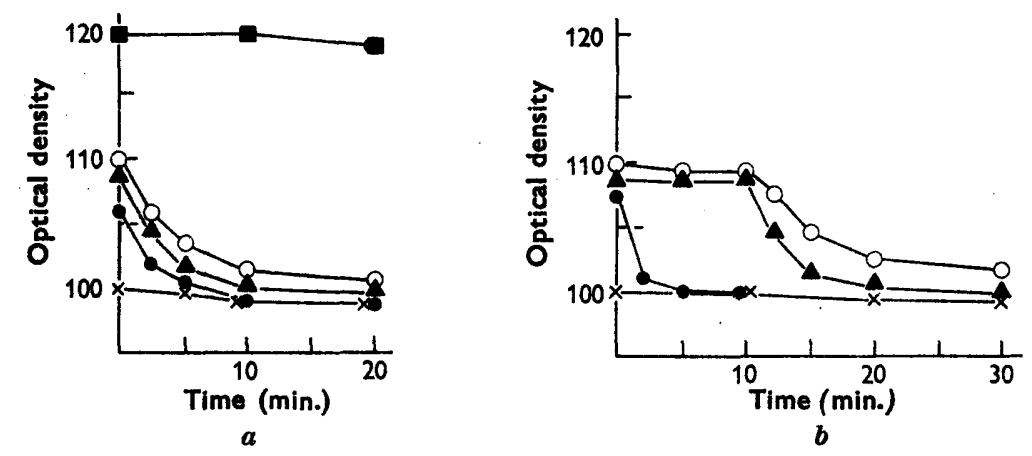

Fig. 2. The changes in the optical density of suspensions of the pseudomonad in amino acid solutions buffered with $\mathrm{M} / 200$ phosphate buffer $\mathrm{pH} 7 \cdot 2$. $a$, With gentle agitation; $b$, bacteria and amino acid mixed under evacuated conditions and air admitted after $10 \mathrm{~min}$. Optical densities are expressed as percentage initial optical density in $M / 200$, phosphate buffer pH 7.2. - $-0.25 \mathrm{M}-\mathrm{NaCl} ;-x-, \mathrm{m} / 200$ phosphate buffer; - - $0.26 \mathrm{M}$-I-arginine HCl, $-\Delta-, 0.26 \mathrm{M}-\mathrm{L}$-citrulline; - $-0.25 \mathrm{M}-\mathrm{L}$-ornithine HCl.

If these results, obtained using an amino acid concentration of $0.25 \mathrm{M}$, are applicable to experiments performed using $0.5 \mathrm{~mm}$ concentration it is apparent that they are in accord with the observation that citrulline can only promote motility after a period of aeration which allows amino acid to enter the cell. The explanation is not completely satisfactory however since it is not clear why arginine should be decomposed only under anaerobic conditions, when permeability is least, or, on the other hand, why citrulline is not metabolized under the same conditions. The findings of these experiments may, however, be summarized by saying that variations in permeability to citrulline under aerobic and anaerobic conditions may provide a partial explanation of the ability of citrulline to activate motility only after a period of aeration in citrulline. The increased permeability to the two amino acids occurring under aerobic conditions suggests that permeation takes place by activated uptake rather than by simple diffusion. 


\section{DISCUSSION}

The experiments described have shown that the hydrolysis of arginine which occurs during arginine-activated motility proceeds with citrulline as an intermediate. This mode of breakdown of arginine has been widely reported, especially in bacteria, and the citrulline-decomposing step has been shown to be exothermic both on theoretical grounds (Knivett, 1954a) and by demonstration of ATP formation. It is also possible that the arginine desimidase reaction is also exothermic. No thermodynamical data are available which would indicate whether ATP formation in this step is possible, but Ratner \& Petrack (1951) have shown that ATP is necessary for the reverse reaction; it is therefore possible that the hydrolysis could involve ATP formation.

If it is assumed that only one molecule of ATP is formed from the hydrolysis of each molecule of arginine it can be calculated that the reaction releases energy at a rate of about $2 \times 10^{-8} \mathrm{ergs} / \mathrm{cell} / \mathrm{sec}$. The power required to drive an organism having the form of a prolate spheroid $0.5 \times 2.0 \mu$ at a rate of $10 \mu /$ sec. can be shown by a calculation based on Stokes's Law (Morowitz, 1952) to be $c \cdot 10^{-10} \mathrm{ergs} / \mathrm{cell} / \mathrm{sec}$. This result shows that even when allowance has been made for the inefficiencies of the conversion of chemical energy to the mechanical energy of motility there is sufficient energy available from the hydrolysis of arginine to propel the organism at a reasonable speed, and it is therefore possible for arginine to provide all the energy for motility.

This hypothesis leads to the expectation that citrulline will activate motility and this has been shown to be correct. The motility activated by citrulline occurred, however, only after pre-aeration in the presence of citrulline and was unlike arginine-activated motility in that its duration was independent of citrulline concentration above $0.2 \mathrm{mM}$ and it was not as vigorous as that found in the presence of arginine. These features can be explained by the experimental evidence. The cells of the pseudomonad are more permeable to citrulline under aerobic conditions, and aeration in the presence of citrulline allows the amino acid to enter the cell until a certain limiting concentration is reached; when conditions become anaerobic breakdown of citrulline commences. With a suspension containing $0.5 \mathrm{mg}$. bacterial dry wt./ml. this decomposition occurs at a rate of $0.05 \mu \mathrm{mole} / \mathrm{ml} . / \mathrm{hr}$. in the first $5 \mathrm{~min}$. and the rate later decreases. Arginine hydrolysis under similar conditions proceeds at a rate of $1.0 \mu \mathrm{mole} /$ $\mathrm{ml}$./hr. and this explains the difference found in the speeds of motility.

In a previous paper it was suggested that the dependence of anaerobic motility on arginine might be explained by the mediation of arginine in the form of phosphoarginine; it has not been possible to obtain any evidence supporting this and it would now appear to be unlikely. In the same paper it was also suggested that ATP was the agent responsible for activating motility. It has not been possible to demonstrate motility in the presence of ATP, but in view of the widespread role of ATP as a means of energy interchange in systems involving movement (Weber, 1955) this hypothesis would still appear to be feasible.

One aspect of the phenomenon still remains to be explained. The pseudo- 
monad studied breaks down arginine only under anaerobic conditions; under aerobic conditions at $\mathbf{2 3}^{\circ}$ the enzymes are inhibited (Sherris et al. 1957). This inhibition is not absolute, however, as some decomposition occurs at $37^{\circ}$ under aerated conditions, and with other strains the reaction may proceed as quickly under aerated as under anaerobic conditions. The inhibition cannot be explained in terms of oxidation-reduction potential since in cell-free extracts the reaction proceeds in the presence of oxygen, and addition of a reducing agent causes little increase in the rate of reaction. Neither can the inhibition be explained by variations in permeability to arginine since the amino acid passes more quickly into the cell under aerobic than under anaerobic conditions. It is therefore possible that substances present in the cell affect the enzyme system. Compounds known to do this in studies with cellfree extracts are ADP and ATP; the former is necessary for the citrulline ureidase reaction and the latter inhibits it when in excess concentration (Slade, 1955). It is possible that under aerobic conditions the ADP of the cell is involved in oxidative metabolism and is not available for the arginine dihydrolase system. Under aerobic conditions it also seems that the release of energy, as judged by the rate of motility, is higher and the ATP concentration is likely to be higher. If these hypotheses are correct it is apparent that the functioning either of ADP as an activator or ATP as an inhibitor would lead to inhibition of the arginine dihydrolase under aerobic conditions.

We should like to thank Professor A. H. Ennor for providing a sample of phosphoarginine, Dr H. D. Slade for a strain of Pseudomonas sp. and Dr B. A. D. Stocker for preparing purified flagella. One of us (J.G.S.) wishes to acknowledge the receipt of an Agricultural Research Council Junior Fellowship.

\section{REFERENCES}

Archibald, R. M. (1944). Determination of citrulline and allantoin and demonstration of citrulline in blood plasma. J. biol. Chem. 156, 121.

Chinard, F. P. (1952). The photometric estimation of proline and ornithine. J. biol. Chem. 199, 91.

Ennor, A. H., Morrison, J. F. \& Rosenberg, H. (1956). The isolation of phosphoarginine. Biochem. J. 62, 358.

Hrus, G. M. (1940). Ammonia production by pathogenic bacteria. Biochem. J. $34,1057$.

KNIVETT, V. A. (1954a). Phosphorylation coupled with anaerobic breakdown of citrulline. Biochem. J. 56, 602.

KNIVETT, V. A. (1954b). The anaerobic interconversion of ornithine and citrulline by Streptococcus faecalis. Biochem. J. 58, 480.

Korzenovsky, M. \& Werkman, C. H. (1952). Bacterial metabolism of arginine. Arch. Biochem. Biophys. 41, 233.

Lubochinskx, B. \& Zalta, J. P. (1954). Microdosage colorimétrique de l'azote ammoniacal. Bull. Soc. Chim. biol., Paris, 36, 1363.

Mager, J., KuczYnski, M., Schatzberg, G. \& Avi-Dor, Y. (1956). Turbidity changes in bacterial suspensions in relation to osmotic pressure. J. gen. Microbiol. 14, 69.

Mrtchelx, P. (1953). Transport of phosphate across the surface of Micrococcus pyogenes: nature of the cell 'inorganic phosphorus'. J. gen. Microbiol. 9, 273. 
Morowrt, H. J. (1952). The energy requirements for bacterial motility. Physiol. Rev. 87, 186.

OannskY, E. L. \& Gagnia, R. F. (1052). The arginine dihydrolase system of Streptococcus faecalis. J. biol. Chem. 198, 791.

Pregton, N. W. \& Marthand, H. B. (1952). The influence of temperature on the motility of Pasteurella pseudotuberculosis. J. gen. Microbiol. 7, 117.

RAtner, S. \& Petrack, B. (1951). Biosynthesis of urea. III. Further studies on arginine synthesis from citrulline. J. biol. Chem. 191, 698.

Rosenbeng, H., Ennor, A. H. \& Mornison, J. F. (1956). The estimation of arginine. Biochem. J. 63, 153.

Sakaguchi, S. (1950). A new method for the colorimetric determination of arginine. J. Biochem., Tokyo, 37, 281.

Schmmt, G. C., LoanN, M. A. \& TrRan, A. (1952). Degradation of arginine by Clostridium perfringens. J. biol. Chem. 198, 771 .

Sherris, J. C., Preston, N. W. \& Shoesmrit, J. G. (1957). The influence of oxygen and arginine on the motility of a strain of Pseudomonas sp. J. gen. Microbiol. 16, 86.

Srade, H. D. (1958). Hydrolysis of arginine by soluble enzymes of Streptococcus faecalis. Arch. Biochem. Biophys. 42, 604.

Srade, H. D., Doughty, C. C. \& Siamp, W. C. (1954). The synthesis of high-energy phosphate in the citrulline-ureidase reaction by soluble enzymes of Pseudomonas. Arch. Biochem. Biophys. 48, 388.

Slade, H. D. (1955). The metabolism of citrulline by bacteria. Amino Acid Metabolism, ed. W. D. McElroy, \& B. Glass, p. 321. Baltimore: The Johns Hopkins Press.

STocker, B. A. D. (1956). Bacterial flagella: morphology, constitution and inheritance. In Bacterial Anatomy. Symp. Soc. gen. Microbiol. 6, 19.

WEBER, H. H. (1855). The link between metabolism and motility of cells and muscles. Fibrous Proteins and their Biological Significance. Symp. Soc. exp. Biol. 9, 271.

(Received 2 June 1959) 